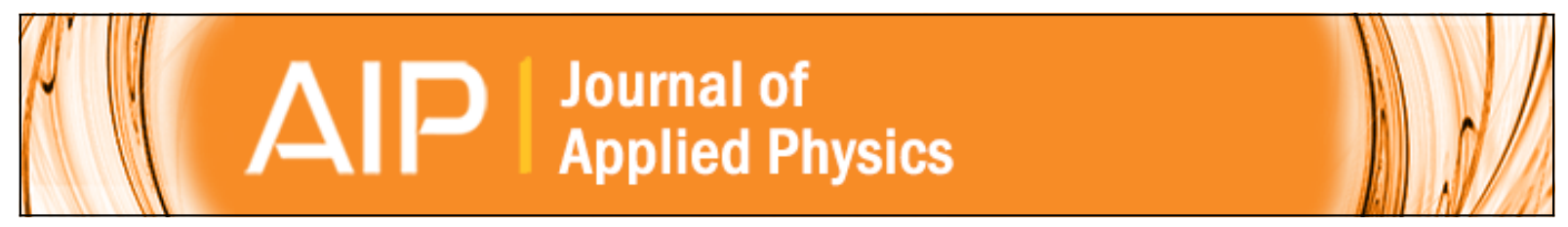

\title{
Nanoporous SiO 2 / Si thin layers produced by ion track etching: Dependence on the ion energy and criterion for etchability
}

\author{
A. Dallanora, T. L. Marcondes, G. G. Bermudez, P. F. P. Fichtner, C. Trautmann, M. Toulemonde, and R. M. \\ Papaléo
}

Citation: Journal of Applied Physics 104, 024307 (2008); doi: 10.1063/1.2957052

View online: http://dx.doi.org/10.1063/1.2957052

View Table of Contents: http://scitation.aip.org/content/aip/journal/jap/104/2?ver=pdfcov

Published by the AIP Publishing

\section{Articles you may be interested in}

Thermal conduction in nano-porous silicon thin film

J. Appl. Phys. 114, 184302 (2013); 10.1063/1.4829913

Microstructure factor and mechanical and electronic properties of hydrogenated amorphous and nanocrystalline silicon thin-films for microelectromechanical systems applications

J. Appl. Phys. 114, 184905 (2013); 10.1063/1.4829020

Fabrication of silicon nanopore arrays using a combination of dry and wet etching

J. Vac. Sci. Technol. B 30, 061804 (2012); 10.1116/1.4766322

Photoacoustic Fourier transform infrared spectroscopy of nanoporous $\mathrm{SiO} \mathrm{x} / \mathrm{Si}$ thin films with varying porosities J. Appl. Phys. 98, 114310 (2005); 10.1063/1.2138376

Generation of ballistic electrons in nanocrystalline porous silicon layers and its application to a solid-state planar luminescent device

Appl. Phys. Lett. 81, 2472 (2002); 10.1063/1.1508165

\section{MIT LINCOLN} LABORATORY CAREERS

Discover the satisfaction of innovation and service to the nation

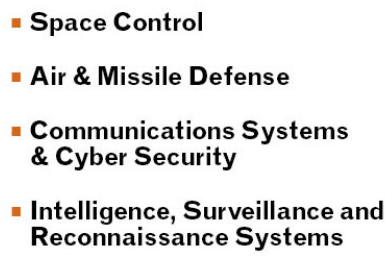

- Space Control

- Air \& Missile Defense

- Communications Systems \& Cyber Security

- Intelligence, Surveillance and Reconnaissance Systems

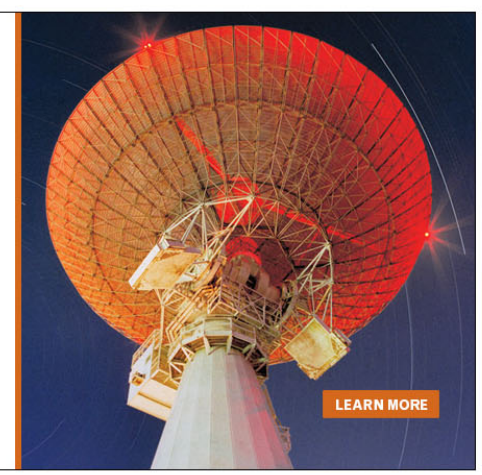

- Advanced

- Tactical Systems

Homeland

Protection

Air Traffic Control 


\title{
Nanoporous $\mathrm{SiO}_{2} / \mathrm{Si}$ thin layers produced by ion track etching: Dependence on the ion energy and criterion for etchability
}

\author{
A. Dallanora, ${ }^{1}$ T. L. Marcondes, ${ }^{2}$ G. G. Bermudez, ${ }^{3}$ P. F. P. Fichtner, ${ }^{2}$ C. Trautmann, ${ }^{4}$ \\ M. Toulemonde, ${ }^{5}$ and R. M. Papaléo ${ }^{1, a)}$ \\ ${ }^{1}$ Faculty of Physics, Catholic University of Rio Grande do Sul, Av. Ipiranga 6681, 90619-900 Porto Alegre, \\ Brazil \\ ${ }^{2}$ Department of Metalurgy, Engineering School, Federal University of Rio Grande do Sul, \\ Av. Bento Gonçalves 9500, 91501-970 Porto Alegre, Brazil \\ ${ }^{3}$ Laboratório Tandar, CNEA, 1429 Buenos Aires, Argentina \\ ${ }^{4}$ Gesellschaft für Schwerionenforschung, Planckstr. 1, 64291 Darmstadt, Germany \\ ${ }^{5}$ CIMAP-ENSICAEN-CEA-CNRS-University of CAEN, Bd H. Becquerel, BP 5133, 14070 Caen Cedex 5, \\ France
}

(Received 5 March 2008; accepted 14 May 2008; published online 21 July 2008)

\begin{abstract}
Vitreous $\mathrm{SiO}_{2}$ thin films thermally grown onto $\mathrm{Si}$ wafers were bombarded by $\mathrm{Au}$ ions with energies from 0.005 to $11.1 \mathrm{MeV} / \mathrm{u}$ and by ions at constant velocity $\left(0.1 \mathrm{MeV} / \mathrm{u}{ }^{197} \mathrm{Au},{ }^{130} \mathrm{Te},{ }^{75} \mathrm{As},{ }^{32} \mathrm{~S}\right.$, and $\left.{ }^{19} \mathrm{~F}\right)$. Subsequent chemical etching produced conical holes in the films with apertures from a few tens to $\sim 150 \mathrm{~nm}$. The diameter and the cone angle of the holes were determined as a function of energy loss of the ions. Preferential track etching requires a critical electronic stopping power $S_{e}^{\text {th }}$ $\sim 2 \mathrm{keV} / \mathrm{nm}$, independent of the value of the nuclear stopping. However, homogeneous etching, characterized by small cone opening angles and narrow distributions of pore sizes and associated with a continuous trail of critical damage, is only reached for $S_{e}>4 \mathrm{keV} / \mathrm{nm}$. The evolution of the etched-track dimensions as a function of specific energy (or electronic stopping force) can be described by the inelastic thermal spike model, assuming that the etchable track results from the quenching of a zone which contains sufficient energy for melting. The model correctly predicts the threshold for the appearance of track etching $S_{e}^{\text {th }}$ if the radius of the molten region has at least 1.6 $\mathrm{nm}$. Homogeneous etching comes out only for latent track radii larger than $3 \mathrm{~nm}$. (C) 2008 American Institute of Physics. [DOI: 10.1063/1.2957052]
\end{abstract}

\section{INTRODUCTION}

The damaged region created around the swift heavy-ion trajectories in dielectric materials often exhibits a different chemical reactivity than the unmodified surroundings. Therefore, when the bombarded region is exposed to an appropriate etching agent, the ion tracks can be developed to tailor micro or nanostructures on surfaces or to modify materials properties. ${ }^{1,2}$ Track etching has been extensively applied in particle detectors ${ }^{1}$ and in the processing of membranes with a narrow distribution of pore sizes, specially using polymeric materials. ${ }^{3}$ Bulk glasses were also investigated in the past, but more recently attention has been given to track etching of thin layers of silicon oxide grown on $\mathrm{Si}$ wafers because of possible applications in connection with microelectronics and $\mathrm{Si}$ technology. ${ }^{4-6}$ For a recent review on ion tracks in crystalline and vitreous $\mathrm{SiO}_{2}$, see Ref. 7 .

In principle, an ion track can be revealed if the etch rate along the track $v_{T}$ is larger than that of the nondisturbed material (the bulk etch rate $v_{B}$ ). The most basic physical criterion of etchability involves the knowledge of a threshold stopping power above which a trail of sufficient damage is produced in the lattice. ${ }^{1,2,8}$ Reported values for the threshold of chemical etching in amorphous silicon oxide $\left(a-\mathrm{SiO}_{2}\right)$ vary from ${ }^{9} 7$ down to $4 \mathrm{keV} / \mathrm{nm}$ at lower velocities, $6,10,11$ showing that it is dependent on the ion velocity. A high con-

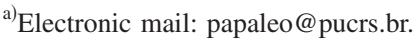

centration of defects along the tracks is usually necessary for successful etching, which implies that the spatial distribution of damage plays a key role in the etchability of an ion track.

Different morphologies were observed in the distribution of damage along the ion penetration depth in oxides at various levels of energy loss. ${ }^{12}$ Electron microscopy observations showed that at low $S_{e}$, only small spherical defects of radii around $1.5 \mathrm{~nm}$ are observed. With increasing stopping power, the defects first appear elongated (but discontinuous) and the radius of the damage region increases until a continuous disordered zone is reached. ${ }^{8,13}$ Continuity of damage is not required for successful etching of tracks, but for uniform pore size distributions. ${ }^{8,14}$

Often the type of defects responsible for the enhanced etching rate along the track of an energetic ion in a given material is much more difficult to define. The enhanced etching rate of bombarded $a-\mathrm{SiO}_{2}$ has been tentatively attributed to the creation of three-membered and four-membered planar rings of $\mathrm{SiO}_{4}$ tetrahedra along the track, with little evidence for a major role of $E^{\prime}$ or oxygen deficient centers. ${ }^{4,15}$ The increased number of small rings, with reduced mean bridging bond angle, has been linked to the observed densification of up to $3 \%$ of irradiated $a-\mathrm{SiO}_{2}$ at large irradiation fluences. ${ }^{15,16}$ Even with a reduced free volume, the strained $\mathrm{Si}-\mathrm{O}$ bonds around the small ring structures may explain the increased etching rate along the track. ${ }^{17}$

Ion track etching is most commonly investigated using 
TABLE I. Stopping powers for the different beams used in this study. Data from SRIM 2003 and CASP 3.2.

\begin{tabular}{|c|c|c|c|c|c|}
\hline$E(\mathrm{MeV})$ & $\begin{array}{l}S_{e}(\mathrm{keV} / \mathrm{nm}) \\
{\text { SRIM } 2003^{\mathrm{a}}}\end{array}$ & $\begin{array}{c}S_{e}(\mathrm{keV} / \mathrm{nm}) \\
\quad \text { CASP- } 3.2^{\mathrm{b}}\end{array}$ & $\begin{array}{l}S_{n}(\mathrm{keV} / \mathrm{nm}) \\
\text { SRIM } 2003\end{array}$ & $\begin{array}{l}S_{\text {tot }}(\mathrm{keV} / \mathrm{nm}) \\
\text { SRIM } 2003\end{array}$ & $\begin{array}{l}S_{\text {tot }}(\mathrm{keV} / \mathrm{nm}) \\
\text { CASP+SRIM }\end{array}$ \\
\hline $1(\mathrm{Au})$ & 1.32 & & 2.98 & 4.30 & \\
\hline 2 & 1.64 & 0.27 & 2.52 & 4.16 & 2.79 \\
\hline 3 & 1.90 & 0.45 & 2.17 & 4.07 & 2.62 \\
\hline 4 & 2.09 & 0.67 & 1.93 & 4.02 & 2.60 \\
\hline 5 & 2.24 & 0.91 & 1.74 & 3.98 & 2.65 \\
\hline 10 & 2.65 & 2.14 & 1.20 & 3.85 & 3.34 \\
\hline 20 & 3.60 & 4.56 & 0.78 & 4.38 & 5.34 \\
\hline 50 & 8.10 & 9.77 & 0.41 & 8.51 & 10.18 \\
\hline 85 & 11.92 & 12.63 & 0.26 & 12.18 & 12.89 \\
\hline 118 & 14.00 & 14.44 & 0.21 & 14.21 & 14.65 \\
\hline 2200 & 20.31 & 20.79 & 0.02 & 20.33 & 20.81 \\
\hline $1.9(\mathrm{~F})$ & 1.48 & 1.06 & 0.02 & 1.50 & 1.08 \\
\hline $3.2(\mathrm{~S})$ & 2.16 & 1.91 & 0.05 & 2.21 & 1.96 \\
\hline 7.5 (As) & 3.15 & 3.00 & 0.18 & 3.33 & 3.18 \\
\hline $13(\mathrm{Te})$ & 3.49 & 3.84 & 0.39 & 3.88 & 4.13 \\
\hline
\end{tabular}

beams of heavy ions at high velocities $(\sim 1 \mathrm{MeV} / \mathrm{u}$ or larger $),{ }^{1-3}$ available only at a few large irradiation facilities around the world. Recently, the prospects of ion track etching with low energy beams $(0.1 \mathrm{MeV} / \mathrm{u}$ or lower), available at standard medium-energy ion implanters, ${ }^{5,6,17-19}$ have also been investigated. This energy regime is suitable for the application of ion tracks in the nanostructuring of thin films and particularly in systems like $\mathrm{SiO}_{2} / \mathrm{Si}$ and other thin layers useful for microelectronic devices. In the wake of lowvelocity heavy ions, a sufficiently high density of excitations in the track is still achievable, but along penetration depths of less than a couple of microns. At low velocities, the damage introduced by the nuclear stopping cannot be neglected. However, the role of the nuclear fraction of the deposited energy in the formation of etchable ion tracks is still under debate and the existence of synergistic effects between nuclear and electronic stopping is unclear.

As compared to a recent work limited to scanning electron microscopy (SEM) observations of the etched surface, ${ }^{6}$ the present work provides scanning force microscopy (SFM) measurements, complemented by some transmission electron microscopy (TEM) observations in cross section, determining the evolution of the size opening and cone angle of the pores as a function of energy loss. Moreover, a very broad range of ion energies is explored, covering the regions of predominance of nuclear energy loss up to the almost fully electronic stopping regime. This allowed us to conclude that the nuclear fraction of the deposited energy has a negligible influence on the formation of etchable tracks in $\mathrm{SiO}_{2}$, even when the nuclear stopping is higher than the electronic one. Furthermore, we applied the inelastic thermal-spike ( $i$-TS) model $^{9,20}$ to rationalize the data on etched pore morphology and size distribution as a function of $S_{e}$. The model can correctly ascribe the threshold stopping power for the appearance of an etchable track and for homogeneous etching, giving support to the idea that the melting of the $a-\mathrm{SiO}_{2}$ structure is directly linked to the etchability of the ion tracks.

\section{EXPERIMENTAL}

Silicon oxide layers $\sim 450 \mathrm{~nm}$ thick were thermally grown onto Si (100) surfaces. A standard RCA (Ref. 21) cleaning was performed before oxide growth in a dry oxygen atmosphere at $1100{ }^{\circ} \mathrm{C}$. Targets were bombarded in vacuum $\left(\sim 3 \times 10^{-6} \mathrm{mbar}\right)$ and at normal incidence with ions from three different accelerators: a 3 MV Tandem at Porto Alegre, Brazil (beam energies from 1 to $20 \mathrm{MeV}$ ), a $20 \mathrm{MV}$ Tandem at Buenos Aires, Argentina (beam energies from 50 to 200 $\mathrm{MeV}$ ), and the UNILAC accelerator at GSI, Darmstadt, Germany $(2200 \mathrm{MeV})$. The fluences were limited to $10^{8}-5$ $\times 10^{9}$ ions $/ \mathrm{cm}^{2}$ in order to minimize etched-track overlap. In one set of experiments, ${ }^{197} \mathrm{Au}$ ions with energies from 1 to $2200 \mathrm{MeV}$ were used. A second group of samples was irradiated by ions of different atomic numbers $\left({ }^{197} \mathrm{Au},{ }^{130} \mathrm{Te}\right.$, ${ }^{75} \mathrm{As},{ }^{32} \mathrm{~S}$, and $\left.{ }^{19} \mathrm{~F}\right)$, but with the same specific energy $(0.1$ $\mathrm{MeV} / \mathrm{u}$ ) and hence velocity.

The irradiation parameters and stopping data are summarized in Table I. Experimental values for the electronic energy loss of $12-37 \mathrm{MeV} \mathrm{Au}$ ions in $\mathrm{C}$ and $\mathrm{Al}$ foils are in good agreement with SRIM 2003 values (within 15\%), ${ }^{22}$ and may also be reasonable for $\mathrm{SiO}_{2}$. At lower velocities, no data is available for $\mathrm{Au}$ ions and we have tried different theoretical estimations (Grande and Schiwietz, ${ }^{23}$ CASP 3.2, ${ }^{23}$ and $\mathrm{Arista}^{24}$ ) to compare to SRIM 2003 extrapolations. For Au energies below $5 \mathrm{MeV}$, the values obtained from the different codes easily vary by a factor of 2 or more. CASP calculations at low velocities are not very precise and stopping values tend to be much smaller than the measured ones. ${ }^{25}$ For the lighter ions (3.2 MeV S and 1.9 MeV F), the discrepancies between SRIM 2003 and CASP 3.2 are much smaller and the agreement with experimental data is good. ${ }^{22}$ Considering the facts above, we chose to use the SRIM 2003 values in all plots. However, one should keep in mind that the uncertainties in $S_{e}$ at $E<0.05 \mathrm{MeV} / \mathrm{u}$ may be large for heavy ions.

The irradiated samples were etched in a $4 \%$ aqueous 


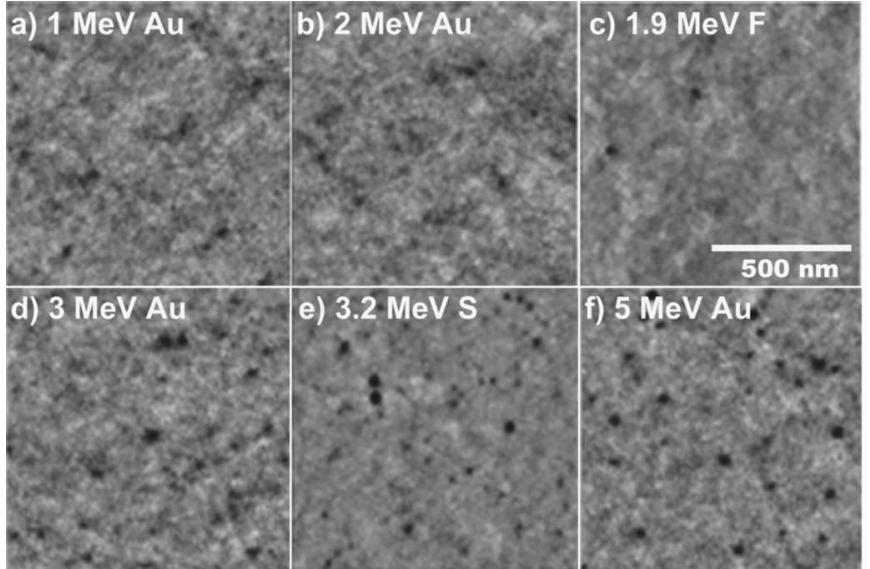

hydrofluoric acid (HF) solution at room temperatures $20-24^{\circ} \mathrm{C}$ for a time $t_{e}=5 \mathrm{~min}$. The two sets of samples ( $\mathrm{Au}$ and fixed velocity irradiations) were etched in sequence from a single batch of solution, using fresh fractions of the solution for each target. After etching, the samples were rinsed in de-ionized water and dried with dry nitrogen gas. Further details on the processing of the pores are given in Ref. 5. The surfaces were imaged by SFM (NanoScope IIIa, Digital Instruments) in the TappingMode ${ }^{\mathrm{TM}}$ under ambient conditions. TEM observations were performed at $200 \mathrm{kV}$ in crosssection specimens prepared by ion milling. Mean values of the etched-pore diameter $D$ and cone angle $2 \beta$, averaged over 50-100 tracks for each specific irradiation, were obtained from SFM images. Cone angles extracted from crosssection TEM images are, in principle, more accurate than those extracted from SFM images, which may be distorted by the finite size of the probe tip. At $2 \beta \geq 150^{\circ}$, however, only SFM can identify clearly the shallow holes.

\section{RESULTS}

\section{A. Hole size}

Figures 1 and 2 show sets of SFM images of etched samples irradiated by different ions at various energies. In

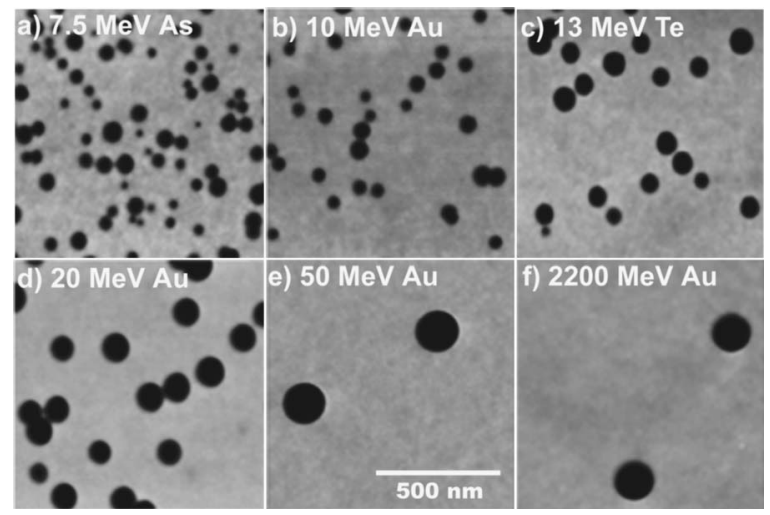

FIG. 2. Series of SFM images showing the evolution of the hole size of the etched tracks for different ion beams. The $S_{e}$ of such ions varies from just above the threshold up to the continuous damage track regime. Images (a), (c), and (d) show typical results for ions at constant velocity $(0.1 \mathrm{MeV} / \mathrm{u})$ and images (b), (e), and (f) for ions with fixed $Z$ at variable velocities. The fluence was not the same in all irradiations. The gray scale covers contrasts in the range of $0-25 \mathrm{~nm}$ in (a)-(c) and $0-50 \mathrm{~nm}$ in (d)-(f). g) $1 \mathrm{MeV} \mathrm{Au}$

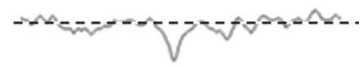

FIG. 1. Series of SFM images showing etched $\mathrm{SiO}_{2}$ surfaces after bombardment with ions near the threshold of etchability. The gray scale covers contrasts in the range of $0-15 \mathrm{~nm}$. The fluence was not the same in all the samples. SFM profiles for the samples bombarded with 1 and $2 \mathrm{MeV} \mathrm{Au}$ ions are shown in $(\mathrm{g})$ and $(\mathrm{h})$, respectively. These profiles were drawn on purpose along a line containing a hole larger than the average roughness level. For comparison in (i) two SFM profiles of a nonbombarded but etched $\mathrm{SiO}_{2}$ surface are shown.

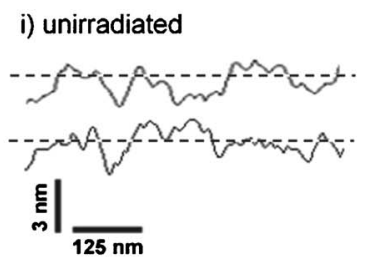

the case of 1-2 MeV Au and $1.9 \mathrm{MeV} \mathrm{F}$ ions $\left(S_{e}\right.$ $<2 \mathrm{keV} / \mathrm{nm}$ ), most of the ion impacts do not result in an etchable track and only a few shallow and poorly defined depressions with irregular contours are visible [Figs. 1(a)-1(c)]. These structures are hard to analyze quantitatively because their boundaries merge with the asperities of the surface roughness [Figs. 1(g) and 1(h))], which may result in substantial overestimation of their diameters. Because of the low etching efficiency and the uncertainties mentioned above, it is assumed that there is virtually no preferential chemical etching along the tracks of ions with $S_{e}$ below $\sim 1.5 \mathrm{keV} / \mathrm{nm}$. On the other hand, a distribution of clearly distinguishable conical cavities appears at energies around 3 $\mathrm{MeV}$ for both $\mathrm{Au}$ and $\mathrm{S}$ ions, corresponding to electronic stopping forces $S_{e}=S_{e}^{\text {th }} \cong 2 \mathrm{keV} / \mathrm{nm}$. Above this threshold, the diameter of the etched pores increases linearly with $S_{e}$ (at variable and constant ion velocities) up to $\sim 5 \mathrm{keV} / \mathrm{nm}$ and then saturates at larger $S_{e}$, reaching a maximum at $\sim 15 \mathrm{keV} / \mathrm{nm}$ (Fig. 3).

The size dispersion of the holes (defined as the standard deviation of the size distribution $\sigma_{D}$ divided by the mean diameter $D$ ) is shown in Fig. 4 as a function of the electronic stopping force. Slightly above $S_{e}^{\text {th }}$, the dispersion of the hole diameters is $\sim 20 \%$ and decreases steeply for larger $S_{e}$ down to values less than $5 \%$ for $S_{e}>5 \mathrm{keV} / \mathrm{nm}$.

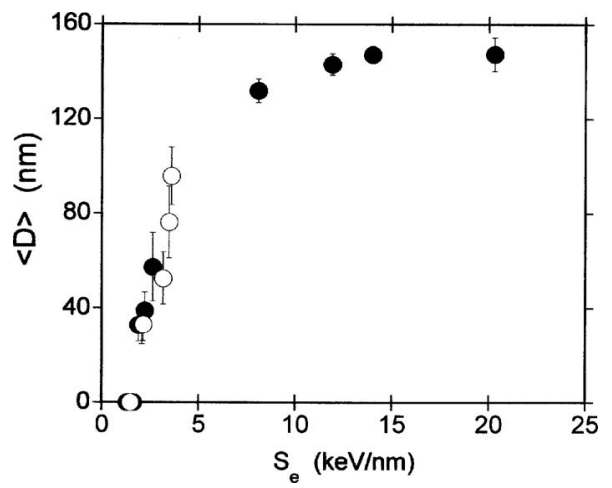

FIG. 3. Mean diameter of etched tracks in $\mathrm{SiO}_{2} / \mathrm{Si}$ films as a function of the electronic stopping power. Filled circles are data for $\mathrm{Au}$ ions and open circles for F, S, As, Te, and Au ions at $0.1 \mathrm{MeV} / \mathrm{u}$. Note that close to the threshold, the majority of events do not produce an etchable track, but some impacts may produce, as it appears, e.g., in Fig. 1. However the average diameter is close to zero. 


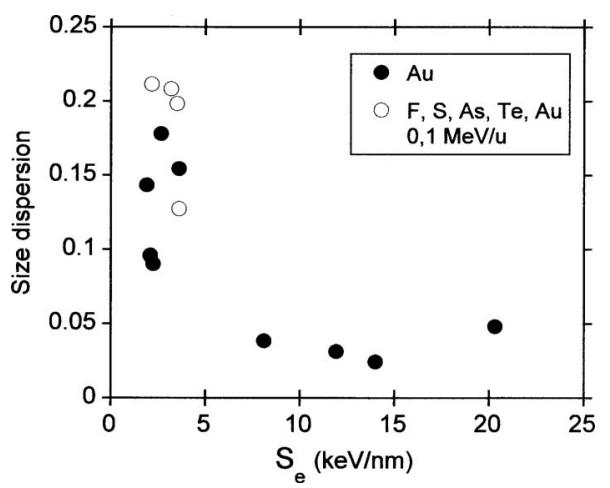

FIG. 4. Relative size dispersion $\left(\sigma_{D} / D\right)$ of the distribution of etched holes as a function of the electronic stopping. Filled circles are data for Au ions and open circles for ions at constant velocity.

A large distribution in the hole diameters is a sign of discontinuous tracks ${ }^{9,14}$ (from the point of view of etching) because of spatial fluctuations in the damage production close to the threshold of etchability. For example, the smaller holes seen in Fig. 2(a) originate from ion tracks for which the minimum damage required for etching is obtained only below the surface. In this case, initially the HF removes, at a similar rate, the track and its surroundings and no opening is produced. If $z_{e}$ is the depth where the first etchable segment of the track is reached, the exposure time to the etchant is reduced, as compared to an etchable track that starts at the surface by an amount $z_{e} / v_{b}$, resulting in smaller holes. The longer the time it takes to reach an etchable structure, the narrower the pore will be. As the damage distribution at low $S_{e}$ is not continuous, $z_{e}$ vary statistically from track to track, resulting in a broad distribution of etched-track diameters.

\section{B. Cone opening angle}

TEM and SFM cross sections of etched tracks produced by $\mathrm{Au}$ ions of various energies are shown in Figs. 5, 1(g), and 1(h). The mean half cone angle of the pores for all different irradiations is shown as a function of $S_{e}$ in Fig. 6 . Close to the threshold of etchability $(\sim 2 \mathrm{keV} / \mathrm{nm})$, wide pores with $\beta \sim 80^{\circ}$ or higher are observed. The shallow and wide-angled conical holes observed show that the etching velocity in the track $v_{t}$ is near the bulk etching velocity $v_{B}(\sim 24 \mathrm{~nm} / \mathrm{min})$. This is a signature of a low density of defects along the track. ${ }^{1,2} \mathrm{~A}$ transition regime is clearly seen between $2<S_{e}<4 \mathrm{keV} / \mathrm{nm}$. For higher energy losses, the half cone angle stabilizes around $18^{\circ}-20^{\circ}$, typical for tracks of high-energy heavy ions in $\mathrm{SiO}_{2} \cdot{ }^{18}$ The constancy of the cone angles and the low level of size dispersion of the pores (Fig. 4) suggest that a continuous trail of critical damage along the ion track is only reached for $S_{e}>4 \mathrm{keV} / \mathrm{nm}$.

\section{DISCUSSION}

\section{A. Thresholds}

The threshold $S_{e}$ values deduced in the present work from TEM and SFM measurements, which define the different regimes of the chemical etching efficiency, are quite in agreement with previous data based on SEM observations. ${ }^{6}$ The observed diameters (corrected for the different etching

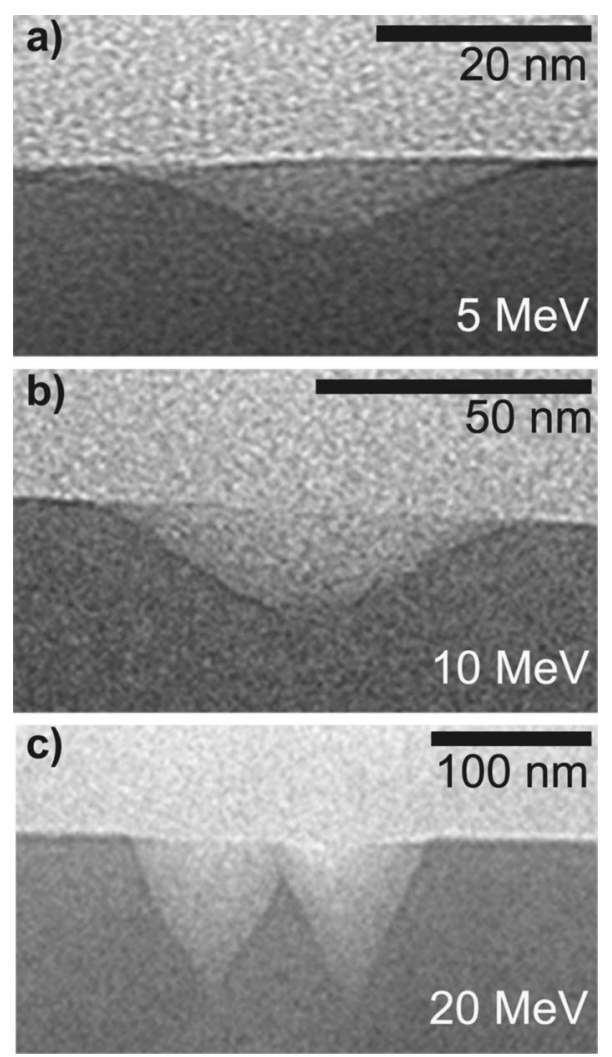

FIG. 5. TEM cross-section images of etched tracks obtained after bombardment with $\mathrm{Au}$ ions of (a) $5 \mathrm{MeV}$, (b) $10 \mathrm{MeV}$, and (c) $20 \mathrm{MeV}$. SFM cross-sections at lower energies (1 and $2 \mathrm{MeV})$ are shown in Fig. 1.

conditions of the two sets of experiments) are also similar within the experimental errors, as can be seen in Fig. 7. The combined data encompass a large variety of ion species and energies. In both sets of experiments, the appearance of the chemical etching occurs at $\sim 2 \mathrm{keV} / \mathrm{nm}$ and narrow poresize distributions (and hence a continuous trail of critical damage along the ion track) are only obtained at $\sim 4 \mathrm{keV} / \mathrm{nm}$. For $S_{e}>4 \mathrm{keV} / \mathrm{nm}$, the number of holes corresponds to the number of ions leading to $100 \%$ etching efficiency. ${ }^{6}$ It should be mentioned that the threshold stopping for chemical etching $S_{e}^{\text {th }}$ appears at a larger $S_{e}$ value than the threshold for damage creation by electronic excitation $[\sim 0.06 \mathrm{keV} / \mathrm{nm}$ (Ref. 26$)$ or less ${ }^{27}$ in the same velocity regime].

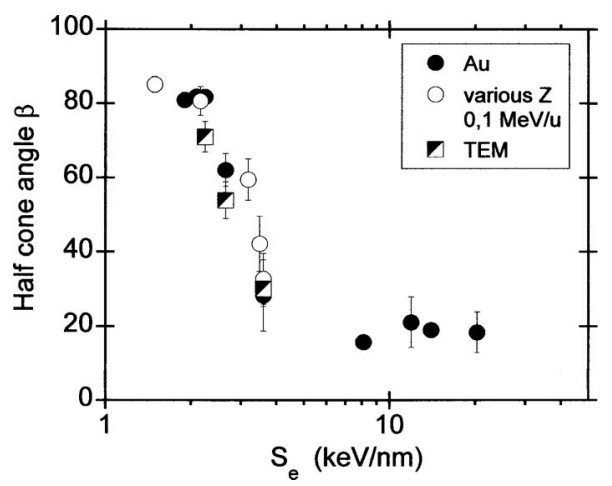

FIG. 6. Mean half cone angle of etched tracks as a function of the electronic stopping power (SRIM 2003). Filled circles are data for Au ions and open circles for ions at constant velocity. Squares are data from TEM for samples bombarded by Au ions. 


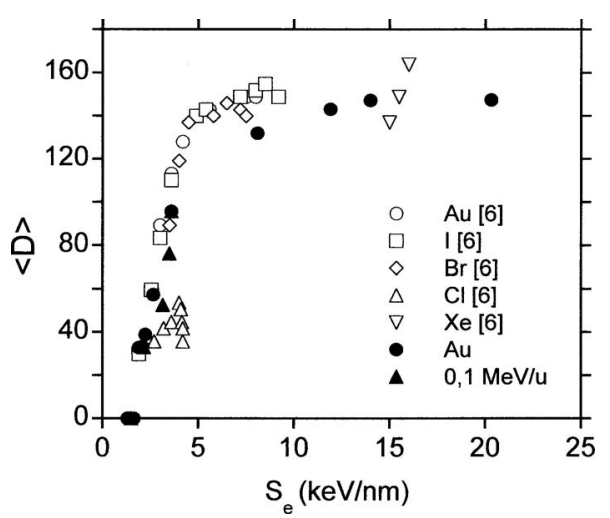

FIG. 7. Etched-track diameter vs electronic energy loss: comparison between Jensen et al. (Ref. 6) and the present experiment. The data from the present work was multiplied by a factor of $4 \times 5 / 4.8 \times 7=0.59$ in order to take into account the different etching conditions.

The constancy of the values of the diameter and cone angles of the etched holes for $0.8<S_{e}<20 \mathrm{keV} / \mathrm{nm}$ indicates that the etchable tracks in this regime are continuous and of similar sizes. The maximum size of the etchable track occurs below the stopping power maximum, this being a characteristic found in many different phenomena related to ion-solid interactions because of the so-called velocity effect. ${ }^{28-31}$ For high velocities, despite the further increase in $S_{e}$, there is an effective decrease in the energy density deposited initially in the tracks due to the higher energy of emitted secondary electrons. For the Au data, this effect is evident for velocities larger than $0.45 \mathrm{MeV} / \mathrm{u}(\sim 90 \mathrm{MeV})$. In this energy regime, the etched-track radii are almost constant, but the electronic energy loss still increases significantly up to 5 $\mathrm{MeV} / \mathrm{u}$ at the maximum of the stopping power.

\section{B. Track etchability and nuclear stopping}

In order to evaluate the role of the nuclear stopping on the etching behavior of the ion tracks in $\mathrm{SiO}_{2}$, the mean hole diameter presented in Fig. 3 was replotted in Fig. 8 in the

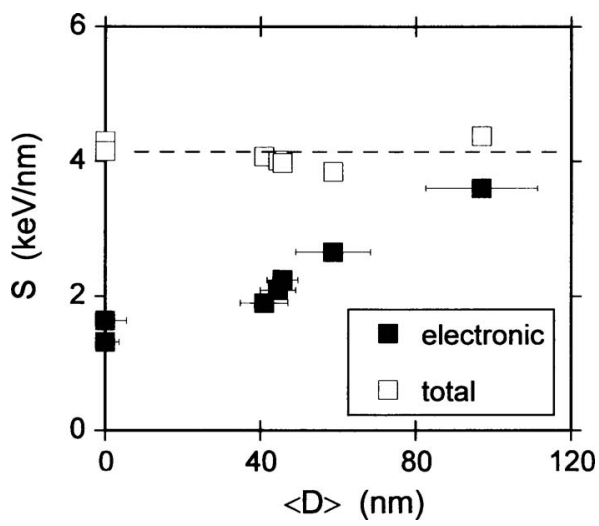

FIG. 8. Correlation between the electronic and total energy losses and the mean etched-track diameter $\langle D\rangle$ in the threshold regime (Au irradiations in the energy range of 1-20 MeV). In order to better elucidate the role of the electronic and nuclear stopping in the etchability of the ion tracks, the total (open squares) and the electronic stopping power (filled squares) are in the $y$-axis and the mean etched-track diameter in the $x$-axis. The dominant role of the electronic stopping in the etching behavior is evident. Stopping forces were extracted from SRIM 2003. threshold regime $\left(S_{e}<4 \mathrm{keV} / \mathrm{nm}\right)$, covering Au irradiations in the energy range of 1-20 MeV. In Fig. 8, the total and the electronic stopping powers are in the $y$-axis and the mean etched-track diameters appear in the $x$-axis. The total energy loss of Au ions in the energy range between 1 and $20 \mathrm{MeV}$ (Table I, SRIM 2003 data) is practically constant and the nuclear component is decreasing while $\langle D\rangle$ increases. Figure 8 clearly illustrates that the diameter of the holes does not correlate with the total stopping.

Moreover, if the nuclear energy deposition was detrimental to the etching process (by annealing or rearranging of the damage introduced by the energy deposited electronically), differences should be observed in the etching behavior of samples bombarded by $4-5 \mathrm{MeV}$ Au and those by 3.2 $\mathrm{MeV} \mathrm{S}$ because such beams have, essentially, the same electronic stopping (close to threshold), but very different nuclear stopping $(\sim 2 \mathrm{keV} / \mathrm{nm}$ for $\mathrm{Au}$ versus $\sim 0.05 \mathrm{keV} / \mathrm{nm}$ for $S$ ). Such differences are not seen, as already noted. If, on the other hand, the nuclear energy deposition was favorable to the etching process, we should see differences in the etching behavior of samples bombarded by $1 \mathrm{MeV} \mathrm{Au}$ and $1.9 \mathrm{MeV}$ F. Both ions have a similar $S_{e}$ $\sim 1.4 \mathrm{keV} / \mathrm{nm}$ close to the threshold, but very different nuclear stopping forces $\left(S_{n} \sim 3 \mathrm{keV} / \mathrm{nm}\right.$ for the Au ions and $S_{n} \sim 0.02 \mathrm{keV} / \mathrm{nm}$ for the F ions). Despite such differences, etched tracks produced by both ions showed a subthreshold behavior. In fact, the requirement for an observable etching is a minimum electronic stopping of $\sim 2 \mathrm{keV} / \mathrm{nm}$, regardless of the value of the nuclear stopping (Fig. 3). We also note that no major differences were seen in the size dispersion or cone angle between irradiations with ions with similar electronic stopping but different nuclear stopping (Fig. 6). That is, the threshold for track continuity seems also to be independent of the nuclear stopping, even when the nuclear energy loss is larger than the electronic one.

In summary, our data suggest that nuclear damage has a negligible action on the etchable type of damage created along the track: no clear synergism effects between the nuclear and electronic energy deposition processes seem to take part, at least in track etching. This is an interesting observation, considering that nuclear displacement energy was found to be much more (500-1000 times) efficient than ionization energy in creating stable point defects in $a-\mathrm{SiO}_{2} .{ }^{15}$

\section{Criterion for etchability and the inelastic thermal spike model}

The simplest phenomenological criterion of etchability of ion tracks which can be put forward is based on the knowledge of a threshold stopping power for the appearance of chemical etching and a second one where uniform etching and maximum efficiency are reached. However, as mentioned previously, because of the importance of the spatial distribution of the deposited energy, such thresholds are not unique, but vary with the ion velocity. ${ }^{31}$ Here we employ the inelastic thermal spike ( $i$-TS) model to calculate the conditions (critical energy density $\varepsilon_{\text {etch }}$ deposited in a specific cylinder) needed to produce an etchable damage structure. 
The $i$-TS model is the only model available to describe quantitatively the threshold of damage creation and the track size in insulators, taking into account the incident ion velocity. ${ }^{8,20,32}$ It tries to establish a link between the initial energy deposition on the electrons and the resulting damage creation in the lattice by introducing the electron-phonon mean free path $\lambda$ that characterizes the length of energy diffusion on the electrons prior to its transfer to the lattice. ${ }^{33} \mathrm{In}$ this model, it is assumed that the induced track size results from a cylinder zone which contains sufficient energy $E_{m}$ for melting (defined by the energy to reach the melting temperature plus the latent heat of fusion ${ }^{20,32}$ ).

The $i$-TS model includes the electrons and the lattice of the target as two independent but coupled subsystems. The energy deposited by the projectiles serves as a heat source term and quickly spreads in the electron subsystem. The subsequent energy exchange from the hot electrons to the cold lattice is governed by the coupling constant $g$ and by the temperature difference between the two subsystems. The energy evolution in the electron and lattice subsystems is mathematically described by two coupled heat equations [Eqs. (1) and (2)]. Since the trajectory of the projectiles can be regarded as straight, the equations are expressed in cylinder geometry with $t$ being the time and $r$ the radial distance from the ion path,

$$
\begin{aligned}
C_{e}\left[T_{e}(r, t)\right] \frac{\partial T_{e}(r, t)}{\partial t}= & \frac{1}{r} \frac{\partial}{\partial r}\left\{r K_{e}\left[T_{e}(r, t)\right] \frac{\partial T_{e}(r, t)}{\partial r}\right\} \\
& -g\left[T_{e}(r, t)-T_{a}(r, t)\right]+A(r, t), \\
C_{a}\left[T_{a}(r, t)\right] \frac{\partial T_{a}(r, t)}{\partial t}= & \frac{1}{r} \frac{\partial}{\partial r}\left\{r K_{a}\left[T_{a}(r, t)\right] \frac{\partial T_{a}(r, t)}{\partial r}\right\} \\
& +g\left[T_{e}(r, t)-T_{a}(r, t)\right],
\end{aligned}
$$

where $T, C$, and $K$ are, respectively, the temperatures, specific heat, and thermal conductivities of the electronic (index $e$ ) and lattice (index $a$ ) systems. $A(r, t)$ is related to the kinetic energy of the projectiles thermalized in the electron system within about $10^{-15} \mathrm{~s} . A(r, t)$ is normalized to ensure that the integration in space and time is equal to the total energy loss $S_{e}{ }^{34}$

The two differential equations are solved numerically as a function of space and time interval $(d t)$, using the electronphonon coupling term $g .{ }^{20,34-36}$ The energy deposited on the electrons is followed assuming the known thermal conductivity. Via the specific heat, the difference in temperature between the electron and lattice subsystems $\left[T_{e}(r, t)\right.$ $\left.-T_{a}(r, t-d t)\right]$ multiplied by $(g \times d t)$ gives the part of the energy transferred to the atomic subsystem during $d t$. Subsequently, the energy is dissipated on the lattice subsystem, providing the energy per atom $E_{a}(r, t)$ and lattice temperature $T_{a}(r, t)$. In the case of insulators, the parameters for the electronic subsystem were previously described, leading to the definition of the electron-phonon mean free path $\lambda$, proportional to the inverse of $g$, which is the only free parameter. $^{20}$

The conversion of the deposited energy to lattice temperature using thermodynamic equilibrium parameters is

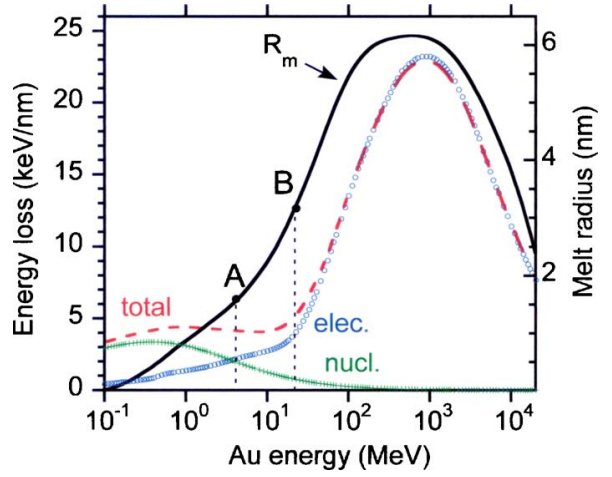

FIG. 9. (Color online) Calculated melt radii from the thermal spike in $a-\mathrm{SiO}_{2}$ for $\mathrm{Au}$ ions of different energies (solid line). The energy losses (electronic, open circles; nuclear, crosses; and total, dashed line) are also shown. Line A indicates the energy $(\sim 4 \mathrm{MeV})$ or $S_{e}(\sim 2 \mathrm{keV} / \mathrm{nm})$ at which the melt radius is $1.6 \mathrm{~nm}$, marking the onset of chemical etching. Line B indicates the energy $(\sim 22 \mathrm{MeV})$ and $S_{e}(\sim 4.2 \mathrm{keV} / \mathrm{nm})$ at which the melt radius is $3.0 \mathrm{~nm}$ marking the onset of damage continuity and uniform etching.

questionable because track formation involves nanoscopic volumes and occurs within an extremely short time period. However, at high temperatures, thermal equilibration can be reached after about ten atomic collisions within $\sim 10^{-13} \mathrm{~s}$, and local thermal equilibrium is probably not unreasonable because at such high temperatures and short time scales, the mean length of energy diffusion in the lattice is at most 0.5 $\mathrm{nm}$. The specific heat for the lattice was deduced from the Dulong-Petit law and the thermal conductivity is constant $(0.01 \mathrm{~W} / \mathrm{cm} \mathrm{K})$ until the vaporization temperature $\left(T_{v}\right.$ $=3223 \mathrm{~K})$ and then increases with the square of the lattice temperature. ${ }^{37}$ The energy necessary for the melting of $a-\mathrm{SiO}_{2}$ is $E_{m}=0.4 \mathrm{eV} /$ atom. ${ }^{9,32}$ In the present case, when the melting (or vaporization) temperature is reached, it is assumed that the temperature stays constant until phase transformation is fully accomplished.

Recently applied in vitreous $\mathrm{SiO}_{2}$, the threshold of damage creation and the track size, obtained experimentally, could be successfully described using $\lambda=3 \mathrm{~nm}$ as an adjustable parameter and the known energy for melting of $a-\mathrm{SiO}_{2}{ }^{9}$ With this value of $\lambda$, the $i$-TS model was applied to the Au beams of different velocities and to the set of ions with constant velocity and different $Z$ to extract the melt radii $\left(R_{m}\right)$ and define the onset of the different etching regimes. $S_{e}$ values were taken from SRIM 2003. The extracted radii are plotted versus the beam energy for the case of Au ions in Fig. 9, together with the electronic, nuclear, and total energy losses. The calculations show clearly that the maximum latent track radius appears quite below the maximum of $S_{e}$ values, as expected from the velocity effect discussed previously.

As seen in Fig. 9, the energy necessary to melt is reached for $S_{e}$ smaller than the appearance of the chemical etching. It is clear that having enough energy for melting is a necessary condition, but it is not sufficient for successful etching. Chemical etching appears for $S_{e}$ larger than $2 \mathrm{keV} / \mathrm{nm}$ (corresponding to a track radius equal to $1.6 \mathrm{~nm}$ ) and is homogeneous for $S_{e}>4 \mathrm{keV} / \mathrm{nm}$ (corresponding to a track radius equal to $3.0 \mathrm{~nm}$ ). Such values are quite in agreement with previous determinations made in several materials (whether 


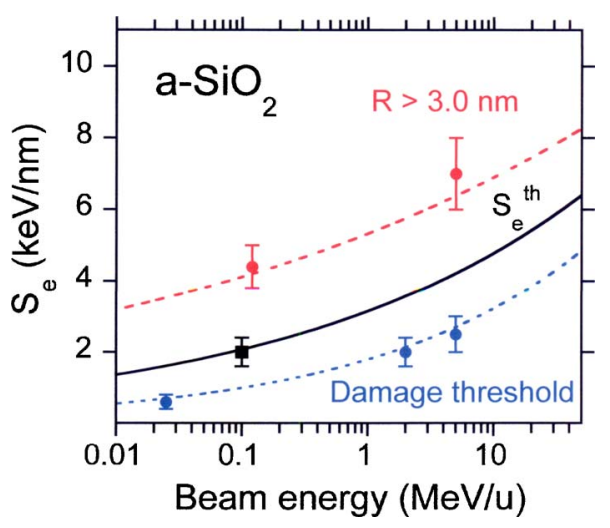

FIG. 10. (Color online) Different thresholds connected to track formation in $a-\mathrm{SiO}_{2}$ derived from the $i$-TS model as a function of the beam specific energy. The short dashed line shows the threshold for damage formation in comparison to experimental data extracted from the following references: Ref. 27 at $0.025 \mathrm{MeV} / \mathrm{u}$, Ref. 40 at $2 \mathrm{MeV} / \mathrm{u}$, and Ref. 9 at $5 \mathrm{MeV} / \mathrm{u}$. The solid line is the threshold to create tracks (melt regions) with radius of 1.6 $\mathrm{nm}$, which defines the start of chemical etching, as observed in the present work and by Jensen et al. (Ref. 6) at an energy of $0.1 \mathrm{MeV} / \mathrm{u}$. The longdashed line shows the threshold to create tracks (melt regions) with a radius of $3 \mathrm{~nm}$, which defines the beginning of homogeneous etching (the experimental points are taken from Refs. 9 and 10).

crystalline $^{8,12,36,38}$ or amorphous ${ }^{39}$ ) based on combined experimental determinations of track damage cross sections, TEM observations, ${ }^{38}$ and measurements of $S_{e}$ thresholds of chemical etching. ${ }^{8,10}$ Typically, etchability appears when the induced damage cross section is $\sim 8 \times 10^{-14} \mathrm{~cm}^{2}$, corresponding to an effective damage radius of $\sim 1.6 \mathrm{~nm}$. With increasing $S_{e}$, the cylindrical damage becomes continuous with a radius larger than $\sim 3 \mathrm{~nm}$, as observed by TEM ${ }^{13}$ and etching becomes efficient with a small hole size dispersion.

From 0.1 until $\sim 4 \mathrm{MeV}\left(S_{e} \sim 2 \mathrm{keV} / \mathrm{nm}\right)$, the calculated $R_{m}$ is always smaller than $1.6 \mathrm{~nm}$ and, accordingly, chemical etching is expected to be inhibited or weak, as observed. Above $25 \mathrm{MeV}$ (and up to $\sim 10 \mathrm{GeV}$ ), $R_{m}>3 \mathrm{~nm}$; thus chemical etching is expected to result in a homogeneous etched-track radius distribution. In the intermediate energy region $(4-20 \mathrm{MeV}), R_{m}$ lies in between 1.6 and $3 \mathrm{~nm}$ and chemical etching is possible but will result in an inhomogeneous distribution of etched-track radii. This description is quite in agreement with the observations of this work and results from Jensen et al. ${ }^{6}$ Calculations performed for the ions of $\mathrm{S}, \mathrm{As}, \mathrm{Te}$, and $\mathrm{Au}$ at constant velocity $(0.1 \mathrm{MeV} / \mathrm{u})$ gave $R_{m}$ values of $1.6,2.5,2.8$, and $2.9 \mathrm{~nm}$, respectively. They all correspond to the intermediate regime of radii where the chemical etching will produce inhomogeneous etched-track radii and half cone angle $\beta$ larger than $20^{\circ}$, again in good agreement with the experimental data. The calculations also allow us to predict the evolution of the three different thresholds (damage threshold, beginning of the chemical etching, and homogeneous etching) versus the specific energy of incident ion for $a-\mathrm{SiO}_{2}$ (Fig. 10, solid lines).

\section{CONCLUSIONS}

The etching behavior of thin $a-\mathrm{SiO}_{2}$ films thermally grown onto Si wafers was investigated in a broad range of ion energies and compared to predictions based on the $i$-TS model. ${ }^{20,32}$ Particular attention was given to the morphology and size fluctuations of the etched tracks and possible combined effects of the nuclear and electronic energy losses for the etchability of the ion tracks at low energies. The requirement for an observable etching is a minimum electronic stopping of around $2 \mathrm{keV} / \mathrm{nm}$, irrespective of the value of the nuclear stopping (even when $S_{n} \approx S_{e}^{\text {th }}$ ). The nuclear damage has a negligible action on the etchable type of damage created along the track. The sharp change in the cone angle and hole-size dispersion, observed for energy losses larger than $\sim 4 \mathrm{keV} / \mathrm{nm}$, defines the transition to a fully cylindrical damage-track geometry and uniform track etching. The evolution of the etched-track radii as a function of specific energy was well reproduced by $i$-TS calculations, assuming that the etchable track results from a zone which contains sufficient energy for melting. The thresholds $S_{e}$ for appearance and for uniform track etching were also correctly predicted if the formation of a molten region in a radius of at least 1.6 and $3 \mathrm{~nm}$, respectively, was used as the criterion. Thus, the present work gives support to the idea that melting and hyperquenching of the $a-\mathrm{SiO}_{2}$ network plays an important role in the etchability of the ion tracks.

Despite the good agreement of the $i$-TS description with the experimental data, there are some important limitations that shall be pointed out. The $i$-TS is a continuous model. The discontinuity of tracks can be considered in the framework of the thermal spike only in an indirect way, as local fluctuations in the energy loss and damage production along the ion path (which are important in the threshold region ${ }^{41}$ ) are not considered. Discontinuity appears through an effective radius, which is narrower than a supposedly discontinuous but broader cylindrical track. The $i$-TS and, to be fair, other standard theoretical approaches ${ }^{1,41,42}$ provide little information on the atomic structure of the latent tracks. Although some information on the $\mathrm{SiO}_{2}$ network following different high temperatures, high pressure, or radiation treatments of $a-\mathrm{SiO}_{2}$ is available, ${ }^{4,16,17}$ both from experiments or simulations, the structure of the defects responsible for the enhanced etch rate of the latent tracks has not been precisely identified. ${ }^{17}$ Clearly, a better view of the chemical arrangement and of the $\mathrm{SiO}_{4}$ ring-size distribution along individual fast ion tracks is needed. Molecular dynamics simulations can help to fill this gap and to provide details of the thermal history and a picture of the track microstructure, which emerge, for example, from similar levels of nuclear and electronic energy depositions.

\section{ACKNOWLEDGMENTS}

We would like to acknowledge the financial support of the Brazilian agencies CNPq, CAPES, and FAPERGS, and DAAD (Germany).

${ }^{1}$ R. L. Fleischer, P. Price, and R. M. Walker, Nuclear Tracks in Solids (University of California, Berkeley, 1975).

${ }^{2}$ R. Spohr, Ion Tracks and Microtechnology (Vieweg, Braunshweig, 1990). ${ }^{3}$ P. Y. Apel and D. Fink, in Transport Processes in Ion: Irradiated Polymers, edited by D. Fink (Springer, Berlin, 2004).

${ }^{4}$ K. Awazu, S. Ishii, K. Shima, S. Roorda, and J. L. Brebner, Phys. Rev. B 62, 3689 (2000) 
${ }^{5}$ C. Milanez Silva, P. Varisco, A. Moehlecke, P. F. P. Fichtner, R. M. Papaléo, and J. Eriksson, Nucl. Instrum. Methods Phys. Res. B 206, 486 (2003).

${ }^{6}$ J. Jensen, A. Razpet, M. Skupinski, and G. Possnert, Nucl. Instrum. Methods Phys. Res. B 246, 119 (2006); 245, 269 (2006).

${ }^{7}$ S. Klaumünzer, Nucl. Instrum. Methods Phys. Res. B 225, 136 (2004)

${ }^{8}$ M. Toulemonde, N. Enault, J. Y. Fan, and F. Studer, J. Appl. Phys. 68, 1545 (1990).

${ }^{9}$ C. C. Rotaru, Ph.D. thesis, University of Caen, 2004; http://tel.archivesouvertes.fr/tel-00005399

${ }^{10}$ A. Sigrist and R. Balzer, Helv. Phys. Acta 50, 49 (1977).

${ }^{11}$ S. Kumar, S. Chander, J. S. Yadav, and A. P. Sharma, Nucl. Instrum. Methods Phys. Res. A 226, 506 (1984).

${ }^{12}$ Ch. Houpert, F. Studer, D. Groult, and M. Toulemonde, Nucl. Instrum. Methods Phys. Res. B 39, 720 (1989).

${ }^{13}$ M. Toulemonde, S. Bouffard, and F. Studer, Nucl. Instrum. Methods Phys. Res. B 91, 108 (1994).

${ }^{14}$ C. Trautmann, R. Spohr, and S. Bouffard, Nucl. Instrum. Methods Phys. Res. B 116, 429 (1996).

${ }^{15}$ R. A. B. Devine, Nucl. Instrum. Methods Phys. Res. B 91, 378 (1994).

${ }^{16}$ M. C. Busch, A. Slaoui, P. Siffert, E. Dooryhee, and M. Toulemonde, J. Appl. Phys. 71, 2596 (1992).

${ }^{17}$ K. Awazu and H. Kawazoe, J. Appl. Phys. 94, 6243 (2003)

${ }^{18}$ R. G. Musket, J. M. Yoshiyama, R. J. Contolini, and J. D. Porter, J. Appl. Phys. 91, 5760 (2002).

${ }^{19}$ F. Bergamini, M. Bianconi, and S. Cristiani, Nucl. Instrum. Methods Phys. Res. B 257, 593 (2007).

${ }^{20}$ M. Toulemonde, C. Dufour, A. Meftah, and E. Paumier, Nucl. Instrum. Methods Phys. Res. B 166-167, 903 (2000).

${ }^{21}$ W. Kern, J. Electrochem. Soc. 1887-1891, 137 (1990).

${ }^{22}$ J. Jokinen, Nucl. Instrum. Methods Phys. Res. B 124, 447 (1997).

${ }^{23}$ P. Grande and G. Schiwietz, Phys. Rev. A 58, 3796 (1998).

${ }^{24}$ N. R. Arista, Nucl. Instrum. Methods Phys. Res. B 195, 91 (2002).

${ }^{25}$ H. Paul (www.exphys.unilinz.ac.at /Stopping)

${ }^{26}$ T. Van Dillen, E. Snoeks, W. Fukarek, C. M. van Kats, K. P. Velikov, A van Blaaderen, and A. Polman, Nucl. Instrum. Methods Phys. Res. B 175-177, 350 (2001)

${ }^{27}$ T. van Dillen, A. Polman, C. M. van Kats, and A. van Blaadaren, Appl. Phys. Lett. 83, 4315 (2003).

${ }^{28}$ A. Albers, K. Wien, P. Dück, W. Treu, and H. Voit, Nucl. Instrum. Methods Phys. Res. B 198, 69 (1982).

${ }^{29}$ R. M. Papaléo, in Fundamentals of Ion Irradiated Polymers, edited by D. Fink (Springer-Verlag, Berlin, 2004), pp. 207-250.

${ }^{30} \mathrm{G}$. Kraft, in Terrestrial Space Radiation and Its Biological Effects, edited by P. D. McCormick, C. E. Swenberg, and H. Bücker (Plenum, New York, 1988), pp. 163-184.

${ }^{31}$ A. Meftah, F. Brisard, J. M. Costantini, M. Hage-Ali, J. P. Stoquert, F. Studer, and M. Toulemonde, Phys. Rev. B 48, 920 (1993).

${ }^{32}$ A. Meftah, J. M. Costantini, N. Khalfaoui, S. Boudjadar, J. P. Stoquert, F. Studer, and M. Toulemonde, Nucl. Instrum. Methods Phys. Res. B 237, 563 (2005).

${ }^{33}$ M. Toulemonde, W. Assmann, C. Dufour, A. Meftah, F. Studer, and C. Trautmann, Mat. Fys. Medd. K. Dan. Vidensk. Selsk. 52, 263 (2006).

${ }^{34}$ C. Dufour, A. Audouard, F. Beneu, J. Dural, A. Hairie, M. Levalois, E. Paumier, and M. Toulemonde, J. Phys.: Condens. Matter 5, 4573 (1993).

${ }^{35}$ Z. G. Wang, C. Dufour, E. Paumier, and M. Toulemonde, J. Phys.: Condens. Matter 6, 6733 (1994).

${ }^{36}$ A. Meftah, F. Brisard, J. M. Costantini, E. Dooryhee, M. Hage-Ali, M. Hervieu, J. P. Stoquert, F. Studer, and M. Toulemonde, Phys. Rev. B 49, 12457 (1994).

${ }^{37}$ P. Sigmund, Appl. Phys. Lett. 25, 169 (1974); P. Sigmund, ibid. 27, 52 (1975).

${ }^{38}$ F. Studer, M. Hervieu, J. M. Costantini, and M. Toulemonde, Nucl. Instrum. Methods Phys. Res. B 122, 449 (1997).

${ }^{39}$ C. Trautmann, C. Dufour, E. Paumier, R. Spohr, and M. Toulemonde, Nucl. Instrum. Methods Phys. Res. B 107, 397 (1996).

${ }^{40}$ A. Benyagoub, S. Loffler, M. Rammensee, S. Klaumünzer, and G. Saemann-Ischenko, Nucl. Instrum. Methods Phys. Res. B 65, 228 (1992).

${ }^{41}$ E. Dartyge and P. Sigmund, Phys. Rev. B 32, 5429 (1985).

${ }^{42}$ T. A. Tombrello Nucl. Instrum. Methods Phys. Res. B 94, 424 (1994). 